\title{
Digestibility of a nutritionally-balanced cassava (Manihot esculenta Crantz) diet and its effect on growth in young male dogs
}

\author{
B Y BER Y L P. KA M A L U \\ Department of Veterinary Pathology and Microbiology, University of Nigeria, Nsukka, Nigeria
}

(Received 2 July 1990 - Accepted 10 December 1990)

\begin{abstract}
Experiments were carried out to study the digestibility of a cassava (gari) diet and its effect on growth in young male dogs. Three groups of dogs were fed on diets with rice (control), cassava (gari), and rice + cyanide respectively as the carbohydrate source. Each diet contained $130 \mathrm{~g}$ crude protein (nitrogen $\times 6.25) / \mathrm{kg}$, was supplemented with vitamins and minerals, and was fed for 14 weeks. Variables measured were body-weight gain, bone growth, plasma alkaline phosphatase $(E C$ 3.1.3.1) activity, total serum 3,5,3'-triiodothyronine $\left(T_{3}\right)$ and some plasma free amino acids. The apparent digestibilities of dry matter, protein and fat were not significantly different in the three groups, but the digestibility of gari fibre was significantly lower than the digestibility of rice fibre when fed to dogs $(P<0.05)$. Proximate analysis of the faeces showed that the group of dogs fed on the gari diet had faeces which had a significantly higher moisture content than the faeces of the other groups $(P<0.05)$, and also a significantly higher fibre content $(P<0.05)$. There was no significant difference in body-weight gain and bone growth between the control and gari-fed groups of dogs, but these variables were significantly lower in the dogs fed on the rice + cyanide $\operatorname{diet}(P<0.05)$. At the end of the 14-week experimental period total serum $T_{3}$ and plasma alkaline phosphatase activity were not significantly different between the control group of dogs and the gari-fed group, but were significantly lower in the rice + cyanide group. Plasma free methionine, leucine, isoleucine and valine concentrations were higher in the rice + cyanide group of dogs than in the control group and the gari group, indicating that these amino acids were accumulating and not being utilized for protein synthesis and growth to the same extent in the rice + cyanide group of dogs as in the other groups. It was concluded that the digestibilities of cassava starch and rice starch were the same in the dog but that rice fibre was more digestible in the dog than cassava fibre. It was also concluded that growth proceeded normally when a balanced gari diet or a balanced rice diet containing $130 \mathrm{~g}$ crude protein $/ \mathrm{kg}$ was fed to dogs, but growth was retarded when a balanced rice + cyanide diet containing $130 \mathrm{~g}$ crude protein $/ \mathrm{kg}$ was fed to dogs because total serum $T_{3}$ concentration became greatly depressed.
\end{abstract}

Cassava diet: Digestibility : Dog

The root of the cassava plant (Manihot esculenta Crantz) is often processed into various products and used as a carbohydrate source in diets of both man and animals. Among humans, the annual per capita consumption of cassava is greatest in Africa (Phillips, 1982), and it is the most important energy source in Southern Nigeria. Among animals, cassava fed to cattle and sheep in various forms produces no obvious ill effects (Hill, 1977) but scientists have reported poor digestibility of cassava diets and depression of growth of pigs and poultry fed on diets containing cassava root (Hill, 1977; Hutagalung, 1977). These observations in pigs and poultry have led to the impression that cassava starch is less readily digested by simple-stomached animals (International Development Research Centre, 1977). 
Table 1. Composition of diets $(\mathrm{g} / \mathrm{kg})$ dry matter

\begin{tabular}{|c|c|c|c|}
\hline \multirow[b]{2}{*}{ Ingredients } & \multicolumn{3}{|c|}{ Diets } \\
\hline & Control & Cassava (gari) & Rice + cyanide \\
\hline Rice & 779 & - & 779 \\
\hline Gari & - & 700 & - \\
\hline Lean pork & 130 & 210 & 130 \\
\hline Bone meal & 75 & 75 & 75 \\
\hline Salt & 15 & 15 & 15 \\
\hline $\begin{array}{l}\text { Vitamin and mineral } \\
\text { supplement, } \\
\mathrm{ml} / \mathrm{kg} \text { food }\end{array}$ & 1 & 1 & 1 \\
\hline $\begin{array}{l}\text { Cyanide, } \mathrm{ml} / \mathrm{mg} \text { food } \dagger \\
(\mathrm{NaCN}) 8.8 \mathrm{mg} / \mathrm{ml})\end{array}$ & 一 & - & 2 \\
\hline
\end{tabular}

* Supplied $\mathrm{mg} / \mathrm{ml}$ of vitamin and mineral syrup, ViDalyn-M ${ }^{\mathbb{B}}$ (Abbott Laboratories, S.A. Spain); retinol 0·18, thiamin hydrochloride $0 \cdot 3$, riboflavin-5-sodium phosphate 0.32 , ascorbic acid 10 , nicotinamide 2 , pyridoxine hydrochloride $0 \cdot 2$, pantothenol 1 , ferrous gluconate $5 \cdot 2$, potassium iodide $19 \cdot 6$, calcium lactate 30 , calcium hypophosphite 16.5 , manganese gluconate 0.9 , zinc glucoheptonate 0.85 , magnesium gluconate $11 \cdot 1$, choline bitartrate $2 \cdot 08$, myc-inositol 1.0 , cholecalciferol $2 \cdot 0 \mu \mathrm{g}$, cyanocobalamin $0 \cdot 6 \mu \mathrm{g}$.

$\dagger$ Approximately equivalent to the level found in the cooked gari diet and added at the time of feeding.

Nicol \& Phillips (1978) reported that the digestibility of rice and cassava diets were the same in young Nigerian men, although the total crude fibre content was lower in rice than in cassava diet.

Delange $e t$ al. (1982) showed that a marked increase in the consumption of cassava in Kivu, Zaire, due to a dramatic food shortage occurring within the area, resulted in low serum levels of the branched-chain amino acids, valine, leucine and isoleucine, but normal serum levels of sulphur amino acids particularly methionine. This pattern of serum amino acids is characteristic of severe protein-energy malnutrition and was consistent with low levels of serum albumin found in these patients.

According to Giesecke (1985) the dog is the species in which nutrition and metabolism is most similar to man. The purpose of the present study was to investigate in young male dogs the digestibility of a nutritionally-balanced cassava diet containing $130 \mathrm{~g}$ crude protein (nitrogen $\times 6.25) / \mathrm{kg}$ and supplemented with vitamins and minerals, and the effect of such a diet on certain indices of growth, namely: body-weight gain, bone growth and plasma alkaline phosphatase (EC 3.1.3.1) activity; total serum 3,5,3'-triiodothyronine $\left(\mathrm{T}_{3}\right)$, and some plasma free amino acids.

\section{MATERIALS AND METHODS}

Animals and diets

Management of the animals and diets was as described by Kamalu (1991).

Briefly, eighteen male dogs of about 6 weeks of age were acquired from village markets. They were routinely treated for endo- and ectoparasites, and given preventative injections against occult disease and anaemia. All animals were fed on a nutritionally-balanced diet for growing dogs with rice as the carbohydrate source, in quantities based on body-weight, for a 4 month pre-experimental period (Gaines Dog Research Center, 1968). Dogs were allocated randomly to the three diets and kept in metabolism cages throughout.

The diets used in the experiment were wet-type cooked food based on rice or cassava, with lean pork, bone meal and vitamin and mineral supplements (Tables 1, 2). Analysis of the diets for their HCN content showed that the gari contained $10.8 \mathrm{mg} \mathrm{HCN} / \mathrm{kg}$ compared 
Table 2. Proximate analysis of wet diet fed to animals $(\mathrm{g} / \mathrm{kg})$

\begin{tabular}{lccc}
\hline \hline Diet*... & Control & Cassava (gari) & Rice + cyanide \\
\hline Water & $709 \cdot 6$ & $727 \cdot 3$ & $709 \cdot 6$ \\
Crude protein & 129 & 131 & 129 \\
$\quad$ (nitrogen $\times 6 \cdot 25)$ & 46 & 53 & 46 \\
Diethyl ether extract & - & - & - \\
Nitrogen-free extract & $1 \cdot 5$ & $5 \cdot 5$ & - \\
Crude fibre & $25 \cdot 27$ & $26 \cdot 65$ & $25 \cdot 27$ \\
Ash & & & \\
Energy $(\mathrm{kJ} / \mathrm{g})$ & &
\end{tabular}

* For details of composition, see Table 1.

with none in the rice diet. In order to monitor the true effects of cyanide, an equivalent amount of free HCN was added to rice as a test diet. The control diet, in which rice provided the carbohydrate source, was fed to dogs in the control (rice) group; the diet in which cassava was used as the carbohydrate source was fed to dogs in the gari group, while the rice diet to which cyanide was added was fed to the dogs in the rice + cyanide group. For the duration of the study the dogs were fed on $500 \mathrm{~g}$ diet once daily. The quantity of food was based on body-weight. Clean water was available ad lib. throughout.

\section{Digestibility of diets and proximate analysis of faeces}

The apparent digestibilities of total dry matter (DM), crude protein, fat and fibre were determined using the quantitative faecal collection method of Crampton \& Lloyd (1959). After a period of 8 weeks from the beginning of the experimental feeding, faecal collections were made over a period of $6 \mathrm{~d}$. Food and faeces were analysed for proximate fractions according to the Association of Official Agricultural Chemists (1975) procedure. The coefficients of apparent digestibility of DM, crude protein, fat and fibre were calculated using values derived from food intake, faecal excretion and proximate analysis.

\section{Determination of body growth by weight gain}

Weighing of the animals was done on day 1 of the experimental period and every $7 \mathrm{~d}$ thereafter until the end of the experimental period, and weight gains calculated. Average daily weight gain (ADWG) was based on total weight gain over the experimental period.

\section{Determination of bone growth by rate of epiphyseal closure using roentgenography}

Roentgenographs of the anterior and lateral aspects of the left forelimb of animals on each diet were taken at intervals and the rate of closure of the proximal epiphysis of the ulna measured. The widths of the uncalcified epiphyseal plates were measured using a microscopic graticule. The reading of the measurement was done using a stereomicroscope.

\section{Biochemistry}

At the end of the experimental period plasma alkaline phosphatase activities were determined using kits supplied by Boehringer Mannheim (Germany); total serum $T_{3}$ concentrations were determined using the enzyme-linked immunosorbent assay (ELISA) principle using a kit supplied by Boehringer Mannheim. Plasma free methionine and the branched-chain amino acids were determined from pooled samples using a Beckman 121 $M$ amino acid analyser. 
Table 3. The mean percentage of digestibilities of diets in growing male dogs for a period of $6 \mathrm{~d}$ beginning 8 weeks after the start of the experiment

(Mean values with their standard errors for six dogs)

\begin{tabular}{|c|c|c|c|c|c|c|c|c|}
\hline \multirow[b]{3}{*}{ Diet ${ }^{+}$} & \multirow{2}{*}{\multicolumn{2}{|c|}{$\begin{array}{c}\text { Dry } \\
\text { matter }\end{array}$}} & \multicolumn{4}{|c|}{ Apparent digestibility coefficients of } & & \\
\hline & & & \multicolumn{2}{|c|}{ Protein } & \multicolumn{2}{|c|}{ Fat } & \multicolumn{2}{|c|}{ Fibre } \\
\hline & Mean & $\mathrm{SE}$ & Mean & $\mathrm{SE}$ & Mean & $\mathrm{SE}$ & Mean & SE \\
\hline Control & $90 \cdot 86$ & 0.005 & $90 \cdot 81$ & $0 \cdot 47$ & $97 \cdot 81$ & $0 \cdot 86$ & 68.98 & $1 \cdot 35$ \\
\hline Cassava (gari) & $91 \cdot 00$ & $2 \cdot 14$ & $87 \cdot 9$ & 1.93 & $96 \cdot 71$ & $1 \cdot 08$ & $0^{*}$ & $0^{*}$ \\
\hline Rice + cyanide & 88.95 & 0.056 & $87 \cdot 7$ & 0.98 & $97 \cdot 44$ & 0.46 & $80 \cdot 40$ & 0.51 \\
\hline
\end{tabular}

Mean values were significantly different from those of the control group: $* P<0 \cdot 05$.

+ For details of diets and dietary regimen, see pp. 200201.

Table 4. Proximate analysis of faeces of growing male dogs for a period of 6 d beginning 8 weeks after the start of the experiment

(Mean values with their standard errors for six dogs)

\begin{tabular}{|c|c|c|c|c|c|c|c|c|}
\hline \multirow[b]{2}{*}{ Diet ${ }^{\dagger}$} & \multicolumn{2}{|c|}{ Moisture content } & \multicolumn{2}{|c|}{ Faecal protein } & \multicolumn{2}{|c|}{ Faecal fat } & \multicolumn{2}{|c|}{ Faecal fibre } \\
\hline & Mean & $\mathrm{SE}$ & Mean & $\mathrm{SE}$ & Mean & $\mathrm{SE}$ & Mean & $\mathrm{SE}$ \\
\hline Control & 66.43 & 0.73 & 15.82 & $0 \cdot 8 \mathrm{I}$ & $1 \cdot 26$ & 0.51 & 1.04 & 0.49 \\
\hline Cassava (gari) & $74.73^{*}$ & 2.04 & $15 \cdot 79$ & 0.06 & $1 \cdot 73$ & 0.47 & $15 \cdot 27^{*}$ & $0 \cdot 14$ \\
\hline Rice + cyanide & $64 \cdot 85$ & $2 \cdot 34$ & $17 \cdot 61$ & $0 \cdot 71$ & 1.71 & 0.53 & $0 \cdot 79$ & $0 \cdot 14$ \\
\hline
\end{tabular}

Mean values were significantly different from those for the control group: ${ }^{*} P<0-05$.

$\dagger$ For details of diets and dictary regimen, see pp. 200201.

\section{Statistics}

The means with their standard errors were calculated where necessary. Analysis of variance (ANOVA) was used to test for differences between treatments. Duncan's (1955) multiple range test was used to separate the means which differ significantly.

\section{RES UL T S}

Digestibility of diets

The mean percentage digestibilities of the diets in the dogs are shown in Table 3 . There were no significant differences in the apparent digestibilities of DM, protein or fat between the three groups $(P>0.05)$. The treatment effect on fibre digestibility was very highly significant $(P<0.001)$. The difference in the digestibility of cassava (gari) fibre compared with control (rice) fibre and rice + cyanide fibre was significant $(P<0.05)$, whereas the difference in digestibility between the control (rice) fibre and rice + cyanide fibre was not statistically significant $(P>0 \cdot 05)$.

\section{Proximate analysis of faeces}

The results of the proximate analysis of the faeces are shown in Table 4. The gari group had the wettest faeces with a moisture content significantly higher than either of the other groups.

Proximate analysis also showed that dietary treatments had no effect on faecal protein 
Table 5. The effects of diets on mean percentage change in weight of growing male dogs during the 14-week experimental period

(Mean values with their standard errors for six dogs)

\begin{tabular}{|c|c|c|c|c|c|c|}
\hline \multirow{3}{*}{$\begin{array}{l}\operatorname{Diet}^{\dagger} \ldots \\
\text { Week }\end{array}$} & \multicolumn{5}{|c|}{ Percentage change in wt } & \multirow{2}{*}{ nide } \\
\hline & \multicolumn{2}{|c|}{ Control } & \multicolumn{2}{|c|}{ Cassava (gari) } & Rice + cyanide & \\
\hline & Mean & SE & Mean & $\mathrm{SE}$ & Mean & $\mathrm{SE}$ \\
\hline 0 & 0 & 0 & 0 & 0 & 0 & 0 \\
\hline 1 & $8 \cdot 46$ & $1 \cdot 80$ & $9 \cdot 73$ & $0 \cdot 13$ & $0 \cdot 98^{*}$ & $0 \cdot 92$ \\
\hline 2 & $10 \cdot 62$ & $3 \cdot 18$ & $14 \cdot 58$ & $2 \cdot 30$ & $6 \cdot 23^{*}$ & $0 \cdot 85$ \\
\hline 3 & $15 \cdot 61$ & 4.07 & $21 \cdot 74$ & $2 \cdot 20$ & $13 \cdot 06^{*}$ & 1.23 \\
\hline 4 & $25 \cdot 03$ & $4 \cdot 19$ & $27 \cdot 87$ & $2 \cdot 41$ & $16 \cdot 47^{*}$ & 1.82 \\
\hline 5 & 33.42 & 4.97 & $35 \cdot 25$ & $2 \cdot 30$ & $25 \cdot 79^{*}$ & 1.54 \\
\hline 6 & $38 \cdot 26$ & $6 \cdot 51$ & $39 \cdot 79$ & $2 \cdot 91$ & $27 \cdot 32^{*}$ & $3 \cdot 26$ \\
\hline 7 & 42.59 & 5.75 & $45 \cdot 75$ & 3.53 & $26 \cdot 68^{*}$ & 1.82 \\
\hline 8 & $52 \cdot 47$ & $7 \cdot 46$ & $55 \cdot 56$ & $4 \cdot 03$ & $35 \cdot 66^{*}$ & 3.6 \\
\hline 9 & 55.55 & 8.46 & $60 \cdot 14$ & $4 \cdot 21$ & $3688^{*}$ & $3 \cdot 21$ \\
\hline 10 & $60 \cdot 21$ & $9 \cdot 02$ & $61 \cdot 72$ & 3.85 & $39.02 *$ & $3 \cdot 39$ \\
\hline 11 & $68 \cdot 80$ & $11 \cdot 42$ & $70 \cdot 29$ & $5 \cdot 13$ & $44.97 *$ & 6.33 \\
\hline 12 & $73 \cdot 11$ & $11 \cdot 26$ & $75 \cdot 22$ & $5 \cdot 81$ & $46 \cdot 77^{*}$ & 5.69 \\
\hline 13 & $78 \cdot 15$ & 11.76 & $79 \cdot 42$ & 6.70 & $51 \cdot 24^{*}$ & 6.47 \\
\hline 14 & $80 \cdot 43$ & $12 \cdot 28$ & $83 \cdot 35$ & $5 \cdot 21$ & $53 \cdot 22^{*}$ & $7 \cdot 63$ \\
\hline
\end{tabular}

Mean values were significantly different from those for the control group for the same week: ${ }^{*} P<0.05$.

$\dagger$ For details of diets and dietary regimen, see pp. 200-201.

content or faecal fat content $(P>0.05)$. The dietary treatments, however, affected faecal fibre content $(P<0 \cdot 01)$. The control group and the rice + cyanide group had low faecal fibre contents which were not significantly different. The faecal fibre content of the gari group was significantly higher than the faecal fibre content of both the control and rice + cyanide groups $(P<0 \cdot 05)$.

\section{Body growth}

The dietary treatments had a highly significant effect $(P<0.01)$ on ADWG for the duration of the experiment (Table 7). There was no significant difference in mean ADWG between the control and gari groups. However, both the control and the gari groups had an ADWG that was significantly greater than that of the rice + cyanide group $(P<0.05)$. The weekly increases in weight were similar in both the control group and the gari group. However, the growth of the rice + cyanide group was significantly depressed as early as week $1(P<0 \cdot 05)$. This growth-retarding effect continued until the end of the experiment. Thus, by the end of the 14th week the mean percentage increase in weight was only 53.22 for the rice + cyanide group compared with 80.43 and 83.35 for the control and gari groups respectively (Table 5). Regression analysis showed that growth was linear for all groups (Fig. 1), and the regression coefficients of 5.996, 5.95 and 3.938 for the control, gari and rice + cyanide groups respectively confirm that the growth rate of rice + cyanide group was significantly different from that of the other groups $(P<0.05)$. These results show that although the addition of cyanide to rice depressed growth, the cyanide in gari had no effect on growth.

\section{Bone growth: epiphyseal closure}

Results of the measurement of the width of uncalcified epiphyseal plates are shown in Table 6 and Fig. 2. Epiphyseal closure was significantly influenced by cyanide-containing foods $(P<0 \cdot 01)$. Time effect was also found to be highly significant $(P<0 \cdot 01)$. Interaction 


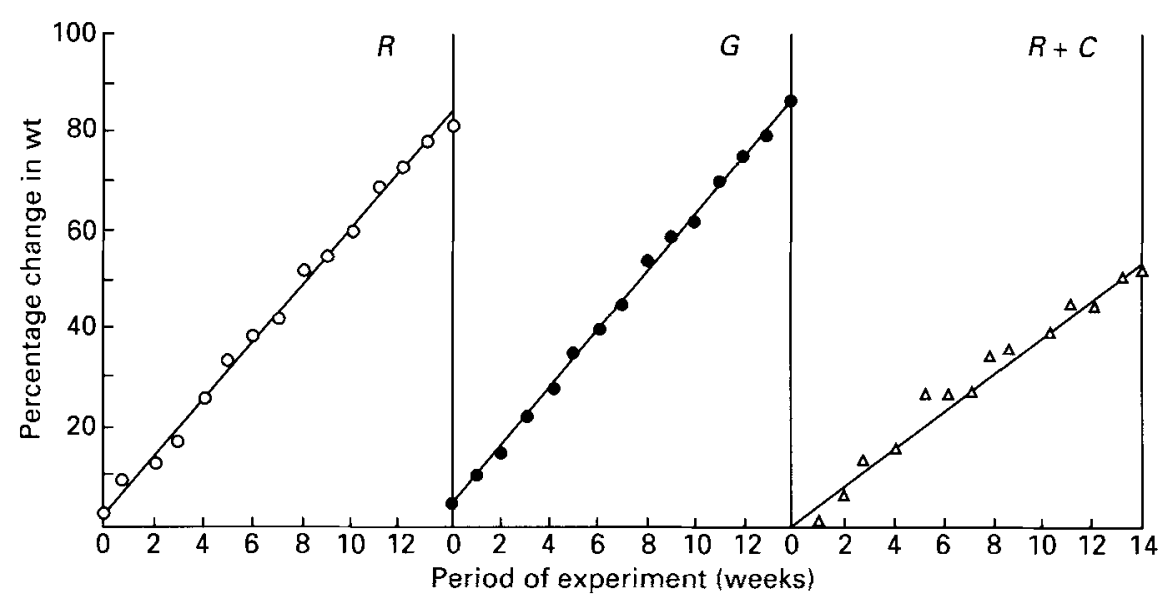

Fig. I. Linear regression of percentage change in weight against time during the experimental period. (O) Dogs fed on the control diet $(\mathrm{R}) ;(\boldsymbol{O})$ dogs fed on cassava (gari) diet $(\mathrm{G}) ;(\triangle)$ dogs fed on rice + cyanide $\operatorname{dict}(\mathrm{R}+\mathrm{C})$. Control (rice), $Y=1.086+5.996 X ; b=5.996$

Cassava (gari), $Y=3.691+5.95 X ; b=5.95$

Rice + cyanide, $Y=0.721+3.938 X ; b=3.938$

For details of diets and dietary regimen, see pp. $200-201$.

Table 6. Effect of diets on mean epiphyseal plate width $(\mu m)$ during the experimental period

(Mean values with their standard errors for six dogs)

\begin{tabular}{cllllll}
\hline \hline & \multicolumn{5}{c}{ Width $(\mu \mathrm{m})$ of uncalcified epiphyseal plate } \\
\cline { 2 - 7 } Diet $\ldots$ & \multicolumn{2}{c}{ Control } & & \multicolumn{2}{c}{ Cassava (gari) } & \multicolumn{2}{c}{ Rice + cyanide } \\
\cline { 2 - 7 } Week & Mean & SE & Mean & SE & Mean & SE \\
\hline 1 & $7 \cdot 85$ & 0.375 & 7.875 & 0.375 & $9 \cdot 25^{*}$ & $1 \cdot 00$ \\
4 & 7.125 & 0.265 & 6.75 & 0.00 & 8.050 & 1.412 \\
12 & $1 \cdot 125$ & 0.2651 & 0.375 & 0.375 & $4.875^{*}$ & $1 \cdot 125$ \\
14 & 0.375 & 0.375 & 0.00 & 0.00 & $3.375^{*}$ & 0.375 \\
\hline \hline
\end{tabular}

Mean values were significantly different from those for the control group for the same week: ${ }^{*} P<0 \cdot 05$.

+ For details of diets and dietary regimen, see pp. $200 \cdots 201$.

between treatment and time was not significant $(P>0.05)$. The effects of control and gari diets were similar, but differed from those of the rice + cyanide diet which significantly inhibited epiphyseal closure $(P<0.05)$. By the end of the first week, the inhibitory effect of the rice + cyanide diet was apparent. This inhibitory effect continued until the end of the experiment. The results indicated that although cassava (gari) contains cyanogenic glucosides, these exerted no inhibitory effect on epiphyseal closure when fed in a balanced diet.

\section{Biochemistry}

The biochemical results are shown in Table 7 . There was no significant difference in the total serum $\mathrm{T}_{3}$ concentration between the control dogs and the gari-fed dogs $(P>0.05)$ at the end of the experimental period, but the $T_{3}$ concentration in the rice + cyanide-fed dogs was significantly lower than in the other two groups $(P<0.05)$. 


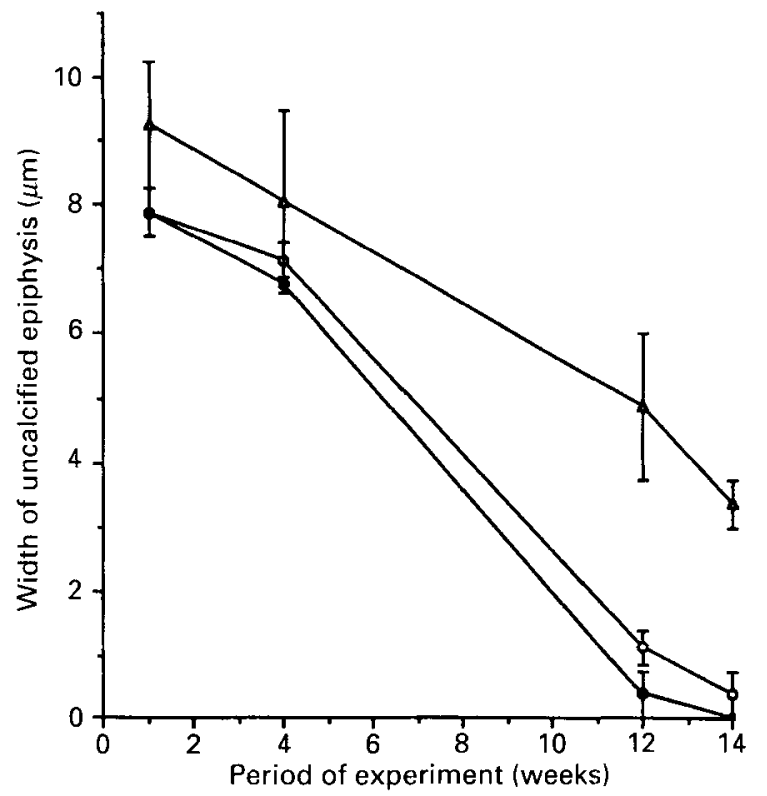

Fig. 2. Variation of mean rate of closure of epiphyseal plates during the experimental period. (O) Dogs fed on control diet; $(\bigcirc)$ dogs fed on cassava (gari) diet; $(\triangle)$ dogs fed on rice + cyanide diet. Points are means with their standard errors represented by vertical bars. For details of diets and dietary regimen, see pp. 200-201.

Table 7. The effect of diets on mean average daily weight gain $(A D W G)(g)$ for the experimental period, 3,5,3'-triodothyronine $\left(T_{3}\right)$ concentration (nmol/l), alkaline phosphatase (EC 3.1.3.1) activity (U/l), plasma free methionine and plasma free branchedchain amino acids (umol/l) after 14 weeks on the experimental diets

(Mean values with their standard errors for six dogs)

\begin{tabular}{|c|c|c|c|c|c|c|}
\hline \multirow{2}{*}{$\begin{array}{l}\text { Diet†... } \\
\text { Variable }\end{array}$} & \multicolumn{2}{|c|}{ Control } & \multicolumn{2}{|c|}{ Cassava (gari) } & \multicolumn{2}{|c|}{ Rice + cyanide } \\
\hline & Mean & $\mathrm{SE}$ & Mean & SE & Mean & $\mathrm{SE}$ \\
\hline ADWG & $40 \cdot 30$ & 3.59 & $43 \cdot 11$ & $4 \cdot 45$ & $25 \cdot 51^{*}$ & $1 \cdot 15$ \\
\hline $\mathbf{T}_{3}$ & $1 \cdot 25$ & 0.05 & $1 \cdot 78$ & 0.04 & $0 \cdot 56^{*}$ & 0.08 \\
\hline Alkaline phosphatase & $397 \cdot 8$ & $22 \cdot 37$ & $449 \cdot 0$ & $87 \cdot 01$ & $319 \cdot 5^{*}$ & 34.67 \\
\hline Methionine & $17 \cdot 16$ & & $22 \cdot 72$ & & $37 \cdot 40$ & \\
\hline Valine & $171 \cdot 81$ & & $128 \cdot 18$ & & 183.77 & \\
\hline Leucine & 101.98 & & $97 \cdot 40$ & & $135 \cdot 52$ & \\
\hline Isoleucine & 55.56 & & $55 \cdot 11$ & & $67 \cdot 30$ & \\
\hline
\end{tabular}

Mean values were significantly different from those of the control group at the end of the experiment: ${ }^{*} P<0 \cdot 05$.

$\dagger$ For details of diets and dietary regimen, see pp. 200-201.

Alkaline phosphatase activities at week 14 showed statistically significant differences between the gari and rice + cyanide groups $(P<0.05)$. This effect indicates the difference in osteoblastic activity in growth and calcification of the bones of the dogs in the two groups. The differences in alkaline phosphatase activities between the control group and gari group were not significant $(P>0.05)$, indicating that there was no difference in osteoblastic activities in the growth and calcification of the bones in these two groups.

The concentrations of the branched-chain amino acids leucine, isoleucine and valine were 
lower in the gari group than in the control group, while the concentration of methionine was higher in the gari group than in the control group. When the quantity of animal protein fed to the gari group is taken into account, these values showed that these amino acids were being utilized at a greater rate for protein synthesis and growth in the gari group than in the control group. Methionine, leucine, isoleucine and valine concentrations were higher in the rice + cyanide group than in the control group and gari group. This indicated that these amino acids were accumulating and not being utilized for protein synthesis and growth to the same extent in the rice + cyanide group.

\section{DISCUSSION}

The present study showed that there were no significant differences in the mean apparent digestibilities of $\mathrm{DM}$, protein or fat in the cassava and rice diets.

It is generally felt that cassava starch is less readily digested by simple-stomached animals than maize starch because it is high in amylopectin and low in amylose (International Development Research Centre, 1977). Johnson \& Raymond (1965) reported that gari, a processed form of cassava, consisted of $200 \mathrm{mg}$ amylose and $700 \mathrm{mg}$ amylopectin $/ \mathrm{g}$. Usually, most natural starches consist of amylose, up to $350 \mathrm{mg} / \mathrm{g}$, and amylopectin, although some maize starch is entirely amylopectin and some pea starch is entirely amylose (Jennings, 1971).

Nicol \& Phillips (1978) found that the apparent digestibilities of rice and gari were the same when fed to young Nigerian men. The present study supports this finding. Methods of preparation of the rice and gari diets were the same in the two experiments, that is, heating in the presence of water, which resulted in the gelatinization of the starches. Gelatinization improves the digestibility of starches (Van Soest, 1982).

Proximate analysis of faeces revealed that the fibre in the gari diet was indigestible, and resulted in a significantly larger percentage of fibre in the faeces and also a greater percentage of water. Rice as a carbohydrate was more digestible than cassava (gari), and the rice diet produced faeces that were less wet than those produced by the gari diet. The similar apparent digestibilities of DM of the two diets were probably due to the fact that the gari diet contained $60 \%$ more lean pork than the rice diet.

Even though the digestibility of the rice fibre was generally greater than that of the cassava (gari) fibre, it was found that when cyanide was added to the rice diet, the fibre content of the faeces was lower than that of faeces with the control diet. It would appear, therefore, that the cyanide in the rice + cyanide diet may have had the effect on the gut microflora of increasing the relative numbers of certain fibre-digesting bacteria.

The present study shows that cassava fibre, but not cassava starch, is less readily digested by dogs.

Growth is influenced by $T_{3}$ (by stimulating synthesis of messenger RNA, protein synthesis and phosphorylation), and is not depressed until total serum $T_{3}$ declines (Barry ef al. 1983). In the present study, both body growth, expressed as weight gain, and bone growth generally followed the pattern of total serum $T_{3}$ concentrations in the three groups of dogs. Growth rate of the group of dogs fed on the rice + cyanide diet was significantly depressed compared with the control and gari groups. This was evidently due to the low total serum $T_{3}$, which would result in the slowing of cellular growth. In addition, low total serum $T_{3}$ concentration causes decreased osteoblastic activity in the primary spongiosa and a resulting decreased alkaline phosphatase activity, impaired chondroitin sulphate synthesis and synthesis of collagen of bone. The total serum $T_{3}$ concentration, therefore, appeared to be positively related to the rate of body growth and bone growth of the dogs in the present study. 
At the end of the experiment, pooled plasma free amino acids were measured for the three groups of dogs. The high concentrations of plasma free methionine in the rice + cyanide group of dogs compared with the other groups, indicated that an adequate amount of methionine was being fed but that it was not being utilized for metabolic activities to the same extent as in the other groups. It is possible that this phenomenon is related mainly to the low total serum $\mathrm{T}_{3}$ concentration and the fact that sublethal levels of cyanide and thiocyanate in the plasma inhibit cellular oxidation and oxidative phosphorylation. All these factors together would produce a decrease in the rate of metabolic activities and consequently a slowing down in the turnover of protein and other cell constituents generally. This finding is at variance with those of Maner \& Gomez (1973) that the addition of methionine to a diet will overcome the depression in growth caused by high levels of cassava or cyanide in the diet.

In protein-energy malnutrition there are low levels of plasma free branched-chain amino acids valine, leucine and isoleucine. In the group of dogs fed on the gari diet, these amino acids were in the lowest concentration even though this group of dogs were fed on a greater amount of animal protein than the other two groups. This finding appears to show a pattern similar to the finding of Delange et al. (1982), who found low serum levels of valine, leucine and isoleucine but normal serum levels of methionine among the cassava-eating people of Kivu, Zaire. The group of dogs fed on the rice + cyanide diet had valine, leucine and isoleucine concentrations higher than those of the other groups. This indicated that the group of dogs fed on the rice + cyanide diet received adequate amounts of protein for growth but were unable to utilize valine, leucine and isoleucine to the same extent as the dogs in the other groups. These findings concur with those of Millward et al. (1976) that the levels of free leucine, isoleucine, valine and methionine were elevated in the muscle of the rat when protein synthesis was depressed, even though these elevations were seen in the muscle, not in the plasma (in the present experiment no analysis for free amino acids in the muscle was done).

The high levels of plasma free amino acids in the rice + cyanide-fed dogs at the end of the experiment appears to be related to a low level of utilization of amino acids as a result of slowing of cellular growth in the presence of adequate levels of nutrients. It seems, therefore, that to ensure normal growth in dogs fed on diets containing cyanide, goodquality protein must be balanced with an adequate amount of iodine to prevent hypothyroidism and a depression of total serum $T_{3}$ concentration. It appears that these requirements were met in the gari diet. After the thyroid and the ovaries, I is present in the highest concentration in the muscles of animals. It may be, therefore, that the high animal protein level in the gari diet supplied a greater amount of I than the rice + cyanide diet, and that the higher I concentration was able to overcome the inhibitory effects of cyanide and thiocyanate on I trapping by the thyroid and the high levels of total serum $T_{3}$ produced allowed growth to proceed normally. In a nutritionally-balanced cassava diet, therefore, starch is readily digested and growth proceeds normally.

\section{REFERENCES}

Association of Official Agricultural Chemists (1975). Official Methods of Analysis, 12th ed. Washington, DC: Association of Official Agricultural Chemists.

Barry, T. N., Duncan, S. J., Sadler, W. A., Miller, K. R. \& Sheppard, A. D. (1983). Iodine metabolism and thyroid hormone relationships in growing sheep fed kale (Brassica oleracea) and ryegrass (Lolium perenne) clover (Trifolium repens) fresh-forage diets. British Joumal of Nutrition 49, 241-253.

Crampton, E. W. \& Lloyd, L. E. (1959). Fundamentals of Nutrition. San Francisco: W. H. Freeman and Co

Delange, F., Bourdoux, P., Colinet, E., Courtois, P., Hennart, P., Lagasse, R., Mafuta, M., Seghero, P., Thilly, C., Vanderpas, J., Yunga, Y. \& Ermans, F. M. (1982). Nutritional factors involved in the goitrogenic action of cassava. In Cassava Toxicity and Thyroid: Research and Public Health Issues. Proceedings of a Workshop held 
in Ottawa, 1982, International Development Research Centre Monograph 207e, pp. 17-26 [F. Delange and R. Ahluwalia, editors]. Ottawa, Canada: International Development Research Centre.

Duncan, D. B. (1955). Multiple range and multiple F tests. Biometrics 11, $1 \div 42$.

Gaines Dog Research Center (1968). Basic Guide to Canine Nutrition 2nd ed. White Plains, New York: General Foods Corporation.

Giesecke, D. (1985). Species differences relevant to nutrition and metabolism research. In Clinical Nutrition and Metabolic Research. Proceedings of the 7th Congress of European Society of Parenteral and Enteral Nutrition, Munich, 1985, pp. 311-328 [G. Dietze, A. Grunert, G. Kleinberger \& G. Wolfram, editors]. Basel: Karger.

Hill, D. G. (1977). Physiological and biochemical responses of rats given potassium cyanide or linamarin. In Cassava as Animal Feed. Proceedings of a Workshop held at the University of Guelph, 1977, International Development Research Centre Monograph 095e, pp. 3342 [B. Nestel and M. Graham, editors]. Ottawa, Canada: International Development Research Centre.

Hutagalung, R. I. (1977). Additives other than methionine in cassava diets. In Cassava as Animal Feed. Proceedings of a Workshop held at University of Guelph, 1977, International Development Research Centre Monograph 095e, pp. 18-32 [B. Nestel and M. Graham, editors]. Ottawa, Canada: International Development Research Centre.

International Development Research Centre, (1977). Discussion conclusions. In Cassava as Animal Feed. Proceedings of a Workshop held at the University of Guelph, 1977, International Development Research Centre Monograph 095e, pp. 127-130 [B. Nestel and M. Graham, editors]. Ottawa, Canada: International Development Research Centre.

Jennings, T. J. (1971). A Background to Biochemistry. Oxford: Pergamon Press.

Johnson, R. N. \& Raymond, W. D. (1965). The chemical composition of some tropical food plants. IV. Manioc. Tropical Science 7, 109-115.

Kamalu, B. P. (1991). The effect of a nutritionally-balanced cassava (Manihot esculenta Crantz) diet on endocrine function using the dog as a model. 1. Pancreas. British Journal of Nutrition 65, 365 372.

Maner, J. H. \& Gomez, G. (1973). Implications of cyanide toxicity in animal feeding studies using high cassava ration. In Chronic Cassava Toxicity. Proceedings of an Interdisciplinary Workshop held in London, 1973, International Development Research Centre Monograph 010e, pp. 113-120 [B. Nestel and R. MacIntyre, editors]. Ottawa, Canada: International Development Research Centre.

Millward, D. J., Garlick, P. J., Nnanyelugo, D. O. \& Waterlow, J. C. (1976). The relative importance of muscle protein synthesis and breakdown in the regulation of muscle mass. Biochemical Journal 156, 185-188.

Nicol, B. M. \& Phillips, P. G. (1978). The utilization of proteins and amino acids in diets based on cassava (Manihot utilissima), rice or sorghum (Sorghtm satina) by young Nigerian men of low income. British Joumal of Nutrition 39, 27I-287.

Phillips, T. P. (1982). An overview of cassava consumption and production. In Cassava Toxicity and Thyroid: Research and Public Health Issues. Proceedings of a Workshop held in Ottawa, 1982, International Development Research Centre Monograph 207e, pp. 83-88 [F. Delange and R. Ahluwalia, editors]. Ottawa, Canada: International Development Research Centre.

Van Soest, P. J. (1982). Nutritional Ecology of the Ruminant, Oregon: O \& B Books Inc. 